\title{
Laser Peening and Shot Peening Effects on Fatigue Life and Surface Roughness of Friction Stir Welded 7075-T7351 Aluminum
}

\author{
Omar Hatamleh ${ }^{1, *}$, Jed Lyons ${ }^{2}$, \& Royce Forman ${ }^{3}$ \\ 1) Structures \& Dynamics Branch, NASA-Johnson Space Center, Houston, Texas 77058 \\ 2) Mechanical Engineering Dept., University of South Carolina, Columbia, South Carolina 29208 \\ 3) Materials \& Processes Branch, NASA- Johnson Space Center, Houston, Texas 77058
}

\begin{abstract}
The effects of laser peening, shot peening, and a combination of both on the fatigue life of Friction Stir Welds (FSW) was investigated. The fatigue samples consisted of dog bone specimens and the loading was applied in a direction perpendicular to the weld direction. Several laser peening conditions with different intensities, durations, and peening order were tested to obtain the optimum peening parameters. The surface roughness resulting from various peening techniques was assessed and characterized. The results indicate a significant increase in fatigue life using laser peening compared to shot peened versus their native welded specimens.
\end{abstract}

Keywords: friction stir welding, laser peening, shot peening, fatigue

\section{Introduction}

Friction stir welding (FSW) (illustrated in Figure 1), was invented by the Welding Institute in England in 1991 [1]. Since then, FSW has emerged as a promising solid state process with encouraging results, particularly when used on high strength aerospace aluminum alloys that are generally difficult to weld. The technique uses frictional heating combined with forging pressure to produce high strength bonds. Significant

\footnotetext{
* Corresponding author. Tel: (281) 483-0286; Fax: (281) 244-5918

Email: omar.hatamleh-1@nasa.gov
} 
applications may be possible in the aerospace, marine, automotive, and railway industries.

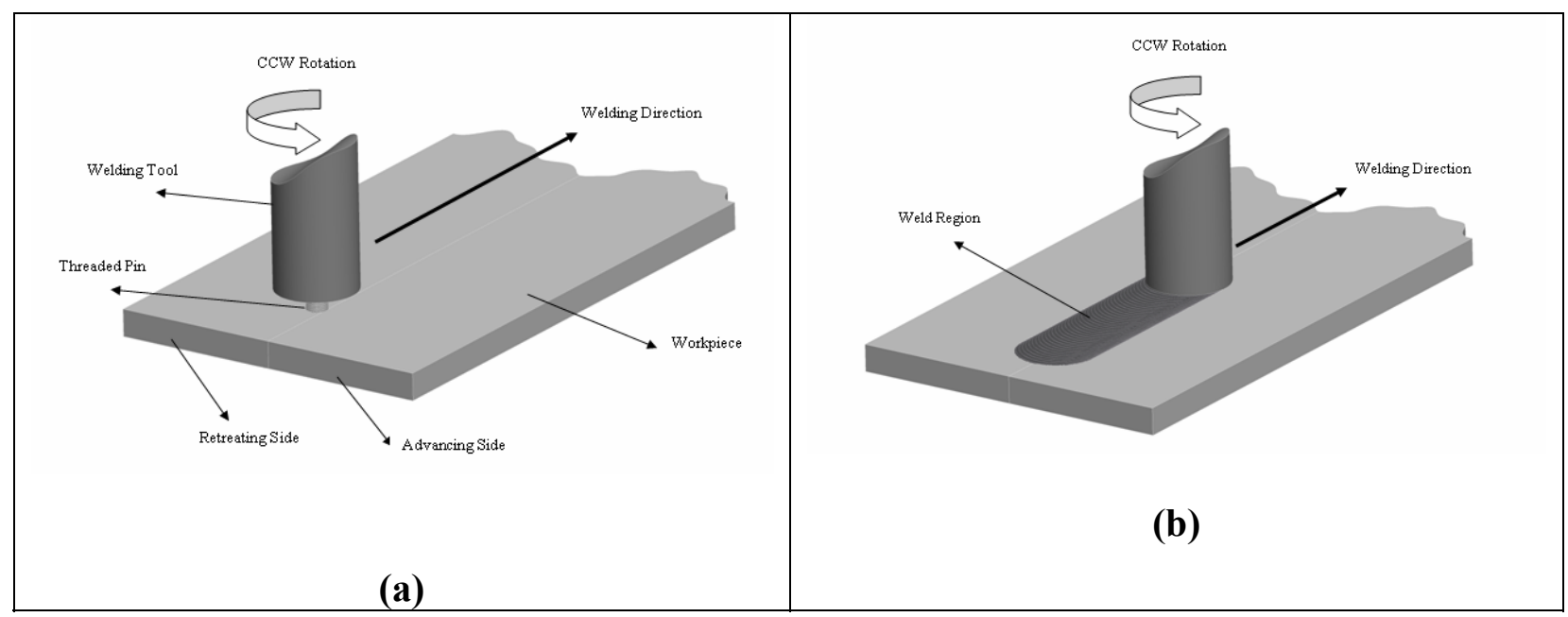

\section{Figure 1 Principle of the friction stir welding process}

The FSW consists of a nugget, or the stirred zone, the thermo-mechanical affected zone (TMAZ), and a heat affected zone (HAZ). The modified microstructure resulting from FSW is asymmetric about the weld centerline [2]. This is due to the advancing and retreating sides of the weld corresponding to maximum and minimum relative velocities between the tool and work-piece [3].

FSW takes place at a low temperature level compared to fusion welding; therefore, residual stresses may be considerably less than those in fusion welds. However, the heating cycle the material experiences during welding, and the rigid clamping arrangement used in FSW can have an impact on residual stresses in the weld. The restraints imposed by the FSW clamps prevent the contraction of the weld nugget and heat affected zone in the longitudinal and transverse direction due to cooling $[4,5]$. This in return will introduce transverse and longitudinal residual stresses in the weld 
region. The residual stresses developed during the welding process can have a significant effect on the service performance of the welded material and can lead to faster crack initiation and propagation.

The use of FSW is expanding rapidly and is resulting in welded joints being used in critical load bearing structures. Therefore, it is important to investigate methods and techniques that can alleviate the tensile residual stresses in welds and extend the fatigue life of those components welded using FSW. Several studies [6-17] has focused on the fatigue behavior of FSW butt-welded aluminum alloys, but none of these studies had investigated the effects of laser peening on the fatigue life.

Laser peening (LP) is a rapidly expanding technology that introduces a state of residual compressive stresses with the ability to develop deep, high compressive stresses in the areas treated. The compressive residual stresses can significantly increases fatigue life and fatigue strength by inhibiting the initiation and propagation of cracks $[18,19]$. Benefits from laser peening have been demonstrated in fields like fatigue, wear, and stress corrosion cracking [20] of aluminum, steels, and titanium alloys. The maximum residual stress for laser peening is usually at the surface, and the residual stress gradually decreases with increasing depth below the surface, whereas for shot peening the maximum residual stress is just below the surface, thus creating a hooked shaped residual stress profile [21].

In this study, laser peening, shot peening and a combination of both were used to introduce compressive residual stresses into FSW AA 7075-T7351. The influence of the various peening techniques on fatigue life and surface roughness was characterized and assessed. 


\section{Experimental Procedures}

The alloy selected for this investigation was the AA-7075-T651. This

precipitation-hardened aluminum alloy is widely used in aerospace applications due to its high strength. The 7075-T651 was supplied as a $0.635 \mathrm{~cm}$ thick plate, with mechanical properties as shown in Table 1.

Table 1. Tensile Properties for the as received AA 7075-T651

\begin{tabular}{|c|c|c|c|}
\hline Material & $\mathbf{0 . 2} \%$ Yield Stress (MPa) & Ultimate Strength (MPa) & Total Elongation (\%) \\
\hline $7075-\mathrm{T} 651$ & 534 & 601 & 11 \\
\hline
\end{tabular}

The FSW specimens were produced at the NASA Johnson Space Center using a 5-axis milling machine. The plates were placed on the welding platform in a butt-weld configuration, and the welding direction was aligned with the rolling direction. The produced FSW panels were $122 \mathrm{~cm}$ x $40 \mathrm{~cm}$ x $0.635 \mathrm{~cm}$.

Since FSW puts the weld nugget microstructure in a supersaturated solid solution condition, heat treatment is necessary to prevent the material from continuing to age at room temperature $[22,23]$. Therefore, following the welding process, the welded plates were aged from the T651 condition to the T7351 condition in accordance with the SAE AMS-H-6088 requirements. The welded plates were then inspected using radiographic and penetrant inspections. The inspections did not reveal any weld defects.

To further qualify the quality of the welds, bending tests using strips specimens with dimensions of $17.8 \mathrm{~cm} \times 2.54 \mathrm{~cm}$ were done. Both the root and the crown sides of the weld were tested. The samples were inspected visually afterward with no crack indications revealed. 
The tensile properties for various locations across the weld zone were characterized by a tensile test using a set of strain gauges as illustrated in Figure 2. The orientation of the specimens was with the weld in the center of the specimen and the load was applied perpendicular to the weld direction. The specimens used were in accordance with ASTM 08 with a specimen width of $12.7 \mathrm{~mm}$. The local strain data was mapped to the corresponding global stress levels by assuming that the transversely loaded FSW specimen was considered a composite material loaded in an iso-stress configuration [24]. Using this assumption, local constitutive stress-strain relationships were obtained.

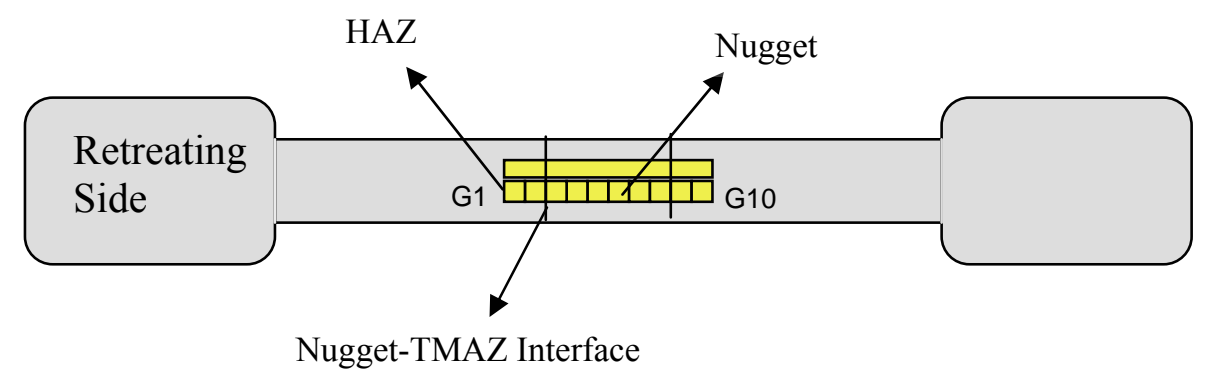

Figure 2 Tensile Specimen strain gauge locations relative to the weld

Microstructural investigation of the weld zone was done using digital, optical, and SEM microscopes. The specimen used for metallographic investigation was cut and sectioned in a direction normal to the welding direction, and then subjected to several successive steps of grinding and polishing until proper surface finish was achieved for a metallographic analysis. After that, the specimen was etched using a Keller's reagent that consists of $190 \mathrm{ml}$ of $\mathrm{H} 2 \mathrm{O}, 5 \mathrm{ml}$ of $\mathrm{HNO} 3,2 \mathrm{ml}$ of HF, and 3ml of HCL. Microhardness test measurements were taken using a 300g for 3 seconds at different regions across the surface of the weld, 
The laser peening process as illustrated in Figure 3 uses high power density laser pulses (several $\mathrm{GW} / \mathrm{cm}^{2}$ ) fired at the surface of a metal coated with an ablative film, and covered with a transparent tamping layer (usually water). As the laser beam passes through the transparent layer and hits the surface of the material, a thin layer of the ablative layer is vaporized. The vapor continues to absorb the remaining laser energy and is heated and ionized into plasma. The rapidly expanding plasma is trapped between the sample and the transparent layer by the inertia of the water, creating a high surface pressure, which propagates into the material as a shock wave [25].

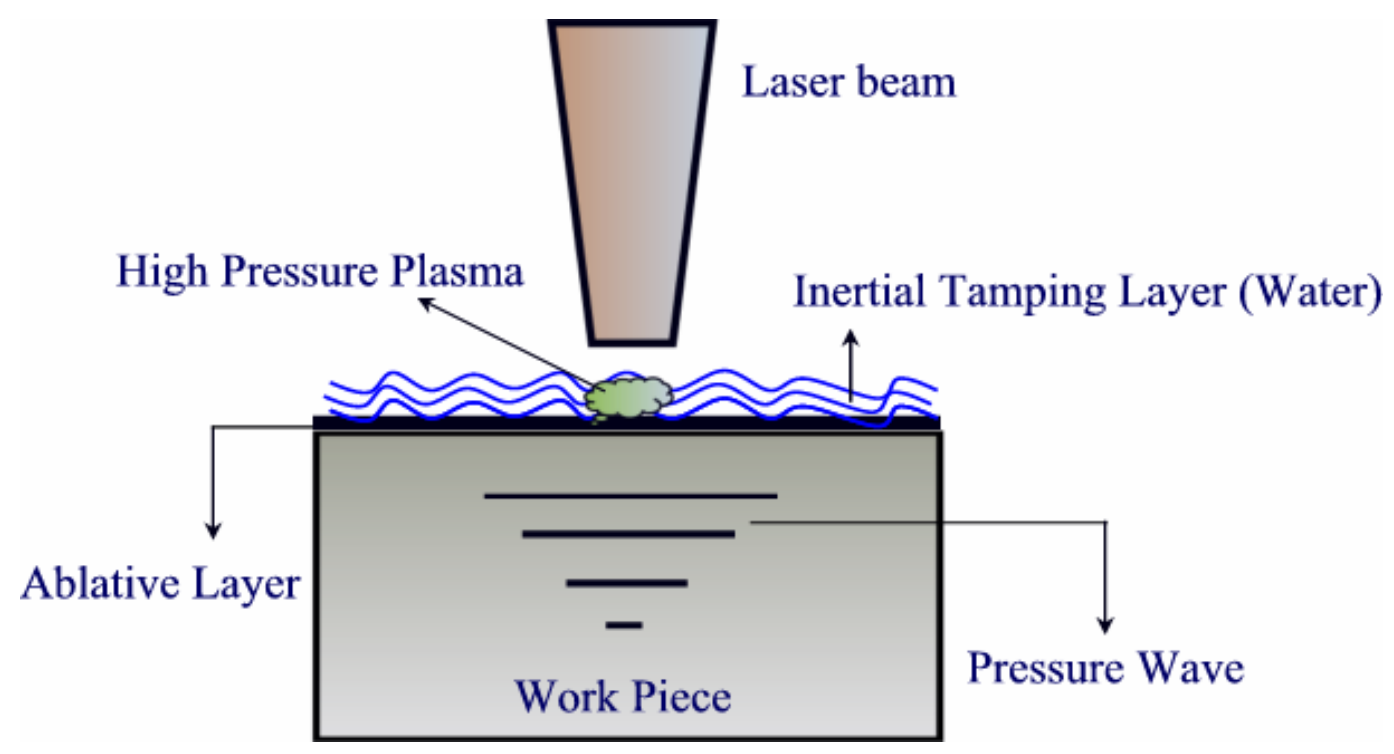

Figure 3 Laser peening process

When the peak pressure of the shock wave is greater than the dynamic yield strength of the material, it produces extensive plastic deformation in the metal. The actual intensity and depths of the LP induced stresses will depend on the processing conditions chosen and the material properties of the component being peened [26]. 
The laser peening was performed at the Metal Improvement Company in Livermore California. The laser system used was capable of relatively high repetition rate of $6 \mathrm{~Hz}$, with a pulse energy of up to $25 \mathrm{~J}$. This can lead to higher application rate of the successive laser spots, which will result in a decrease in the processing time. The surfaces of the specimens intended for peening were covered with an aluminum tape 0.22 mm thick. The aluminum tape was replaced between layers of peening. The tamping layer consisted of an approximately $1 \mathrm{~mm}$ thick laminar layer of flowing water. Before laser peening parameters were chosen, several peening parameters were investigated for best fatigue life performance. The laser intensity, duration, percent coverage, and peening order were varied in an attempt to achieve the best fatigue life. The LP parameters with best performance are illustrated in Figure 4.

Some specimens were laser peened using double layers (200\%), and others using a triple layers (300\%) of surface coverage. A square laser spot size of $4.72 \times 4.72 \mathrm{~mm}^{2}$ with a $2 \mathrm{GW} / \mathrm{cm}^{2}$ laser power density, and 18 nanoseconds duration was used. The spots within a layer were overlapped 3\%. Peening between layers had an off-set of $50 \%$ in each direction. A peening frequency of $2.7 \mathrm{~Hz}$ and a 1 micron wavelength laser were employed. 


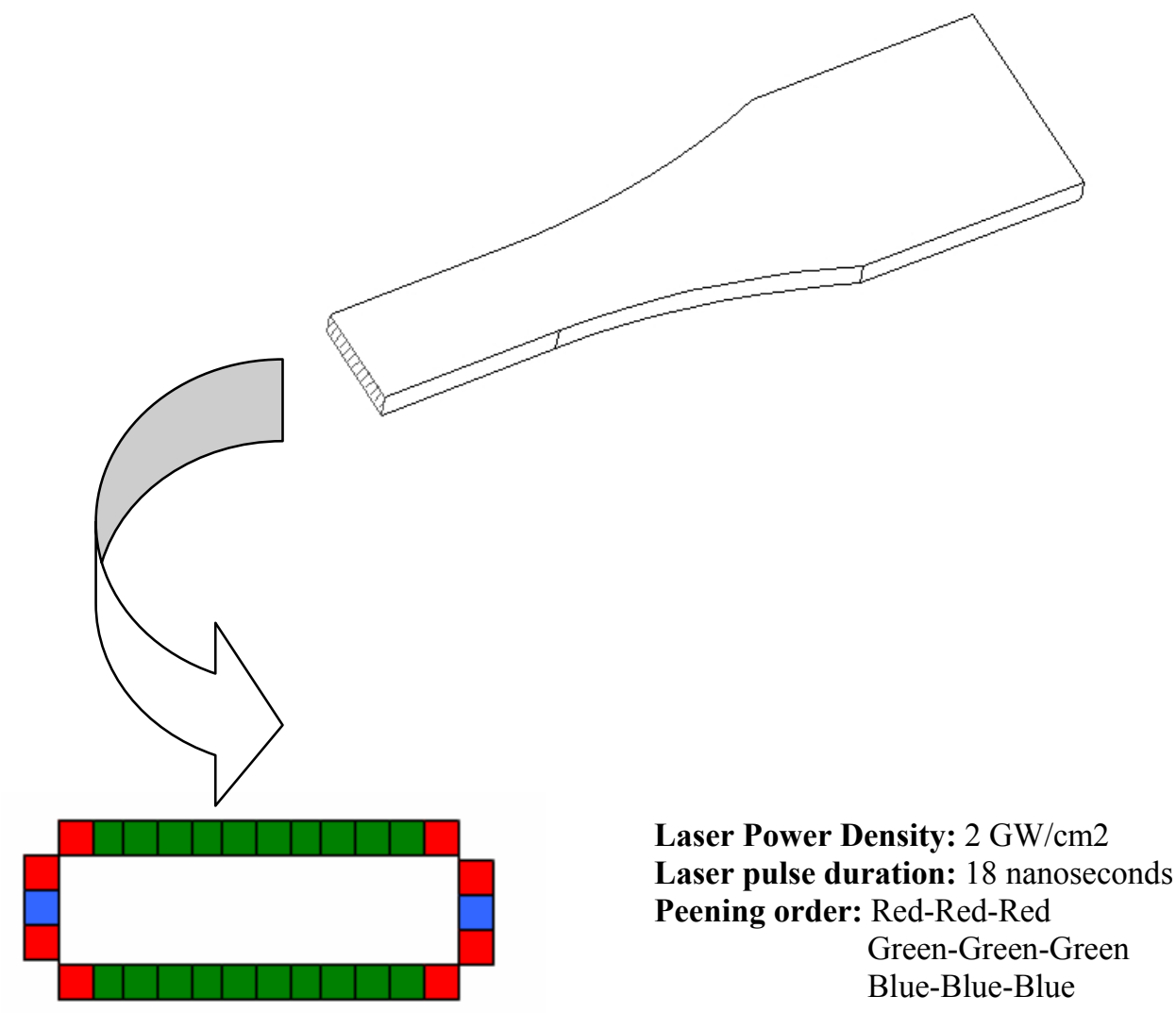

Figure 4 Laser peening profile

During the initial phase of the process development, it was noted that the fatigue life of the specimens were dominated by the corner singularity. Therefore, the corners were rounded to a $2.5 \mathrm{~mm}$ radius in order to better quantify the effects of the different peening techniques.

To optimize the shot peening process, Peenstress which is a software developed at Metal Improvement Company was used. Based on this evaluation, the samples were shotpeened with 0.0234 " glass beads, with an Almen intensity of $0.008-0.012 \mathrm{~A}$ and a $200 \%$ coverage rate. To investigate the effects of combining laser and shot peening on fatigue life, some of the specimens that were processed with two layers of laser were also processed with an extra layer of shot peening. 
Prior to the peening process, the specimens were milled on the top side of the weld removing about $0.4 \mathrm{~mm}$ of material. The coupons were oriented such that the weld was in the center of the specimen and the load was applied perpendicular to the weld direction. The fatigue specimen used in the investigation is illustrated in Figure 5.

The fatigue testing was performed under axial loading at constant amplitude using a servo-hydraulic machine. All the tests took place at a room temperature environment. The maximum stress level used was $190 \mathrm{MPa}$, and was carried out at a stress ratio $\mathrm{R}=0.1$. The loading frequency used in the test was $22 \mathrm{~Hz}$. Failure of the specimens was defined to have taken place when the specimen had separated into two parts.

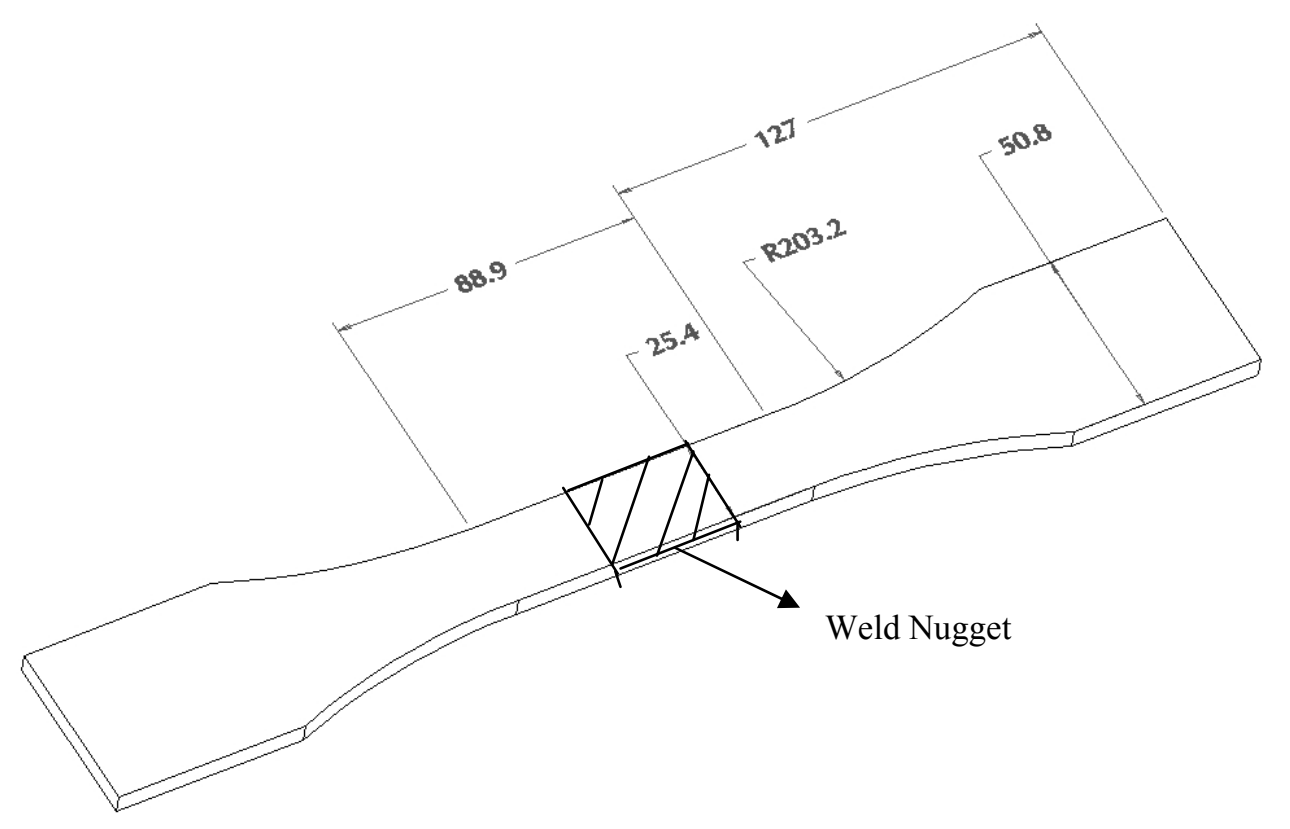

Figure 5 Fatigue test coupon used for testing 
The surface residual stresses for the unpeened, and laser peened FSW specimens using a triple layer were measured using an x-ray diffraction technique. When measuring residual stress measurement using the x-ray diffraction method, the strain in the crystal lattice is measured, and the residual stress producing the strain is calculated, assuming the crystal lattice is linearly distorted. The residual stresses in both the transverse and the longitudinal directions were measured at five locations across the weld as illustrated in Figure 6. The locations corresponded to the weld centerline, weld interface, and the HAZ.

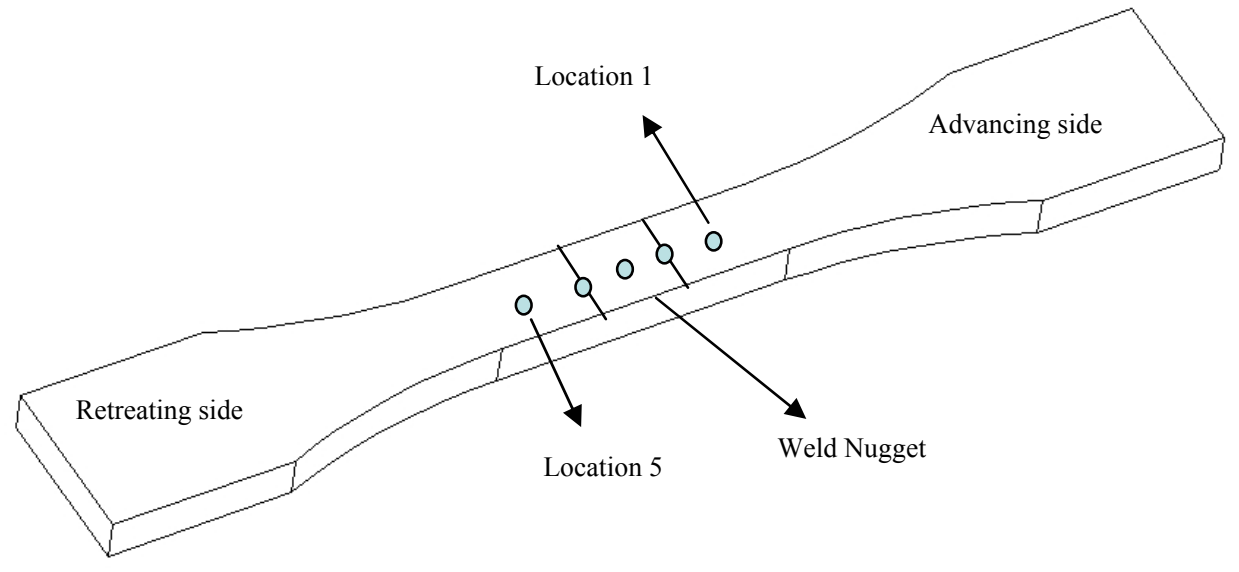

Figure 6 Residual Stress measurements points

In addition, residual stresses in the weld longitudinal direction were measured using the contour method [27] on both unpeened and laser peened specimens as shown in Figure 7. To perform that work, the specimens were cut along the measurement plane with an EDM wire. Before the specimens were cut they were fixed to a rigid backing plate in order to minimize movement during the cutting process. The deformed surface shape resulting from the relaxed residual stresses is measured on both cutting surfaces 
using a coordinate measuring machine (CMM). The displacements from both cutting surfaces are then averaged, and a noise in the measurements is filtered from average displacements by fitting to a smooth analytical surface. Finally, the original residual stresses are calculated from the measured contour using a finite element model (FEM).

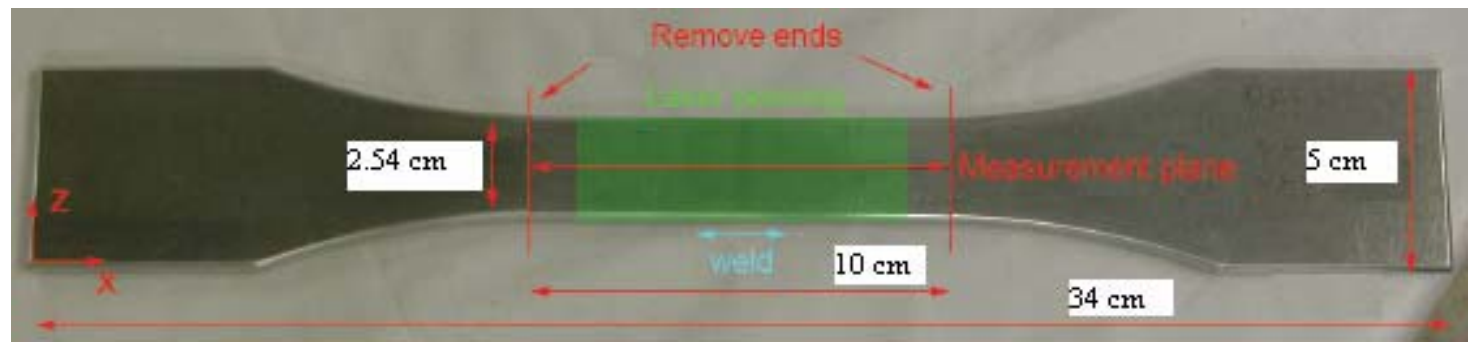

Figure 7 Residual Stress measurement plane using the contour method

Surface roughness profiles for the different peening methods were also characterized, and compared to the base unpeened material. The stylus profilometer (Taylor-Hobson model Form Talysurf PGI-1230) was used to trace the surface profiles. For the 3-D measurements, an $8 \times 8 \mathrm{~mm}$ area was traced with 400 traces evenly spaced. Each trace contained 4000 data points. The 2-D traces were $50 \mathrm{~mm}$ long, with a horizontal sampling of 1000 data points per millimeter. The tracing direction was taken in a direction perpendicular to the weld region. In that way the different regions of the weld were quantified. The stylus had a tip radius of 2 micrometers with a downward force of 80 milligrams. 


\section{Results and Discussion}

\subsection{Weld microstructure and hardness}

A weld cross section showing different regions of the weld is shown in Figure 7. The cross section also illustrates the elliptical onion rings structure in the center of the weld. The FSW samples investigated revealed no visible defects.

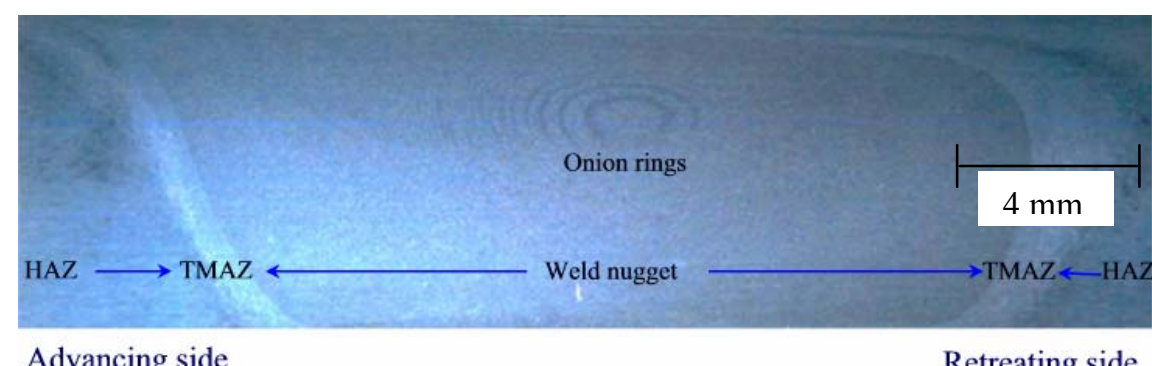

Figure 7 A Cross section of the welded specimen

Another cross section of the weld (Figure 8) illustrates the transition from the nugget- TMAZ-HAZ microstructure on the retreating area of the weld. The grain structure at the nugget is fine and equiaxed grains typical of a re-crystallized structure. The grain sizes in this region are of the order of 5-12 $\mu \mathrm{m}$, and are significantly smaller than the parent material grain due to the higher temperature and extensive plastic deformation. The grain structure at the TMAZ region is elongated, with some considerable distortions that may be attributed to mechanical action from the welding tool. The HAZ is unaffected by the mechanical effects from the tool, and has a grain structure that resembles the parent material grain structure. Even though the grain size in this region resemble the base material, previous work by [28] showed the strengthening precipitates in this region have grown in size and were several times larger than in the parent material. 


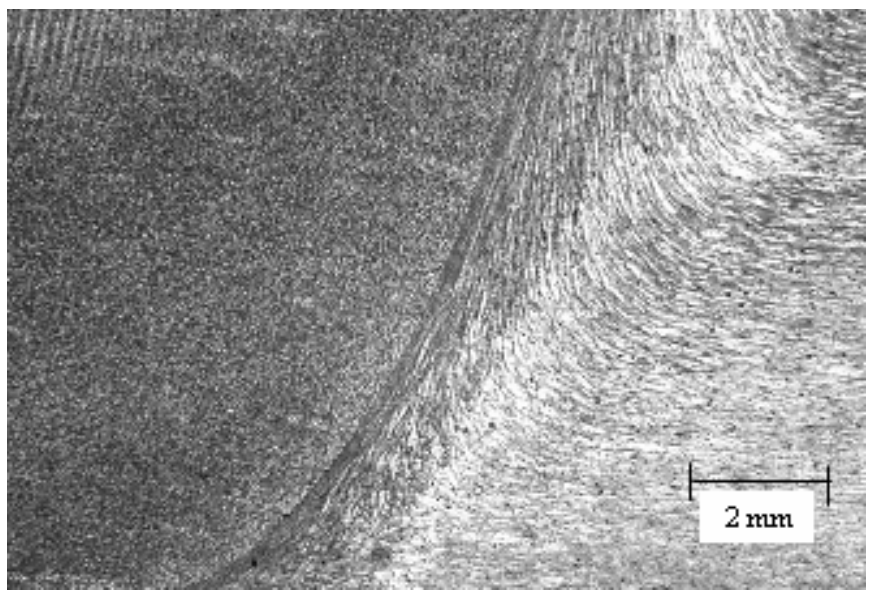

Figure 8 a section of the weld nugget-TMAZ-HAZ interface at 50x

Figure 9 reveals the grain structure at different regions of the nugget. It is noted that the average grain size was different for different regions of the nugget. The grains at the bottom side of the plate were relatively smaller in size than those at the top. This is possibly due to the fact that the bottom surface of the FSW plate is in contact with the backing plate, which may act as a heat sink. Therefore, lower temperatures and shorter thermal cycle at the bottom of the welded plate effectively retards the grain growth and results in smaller grains. 


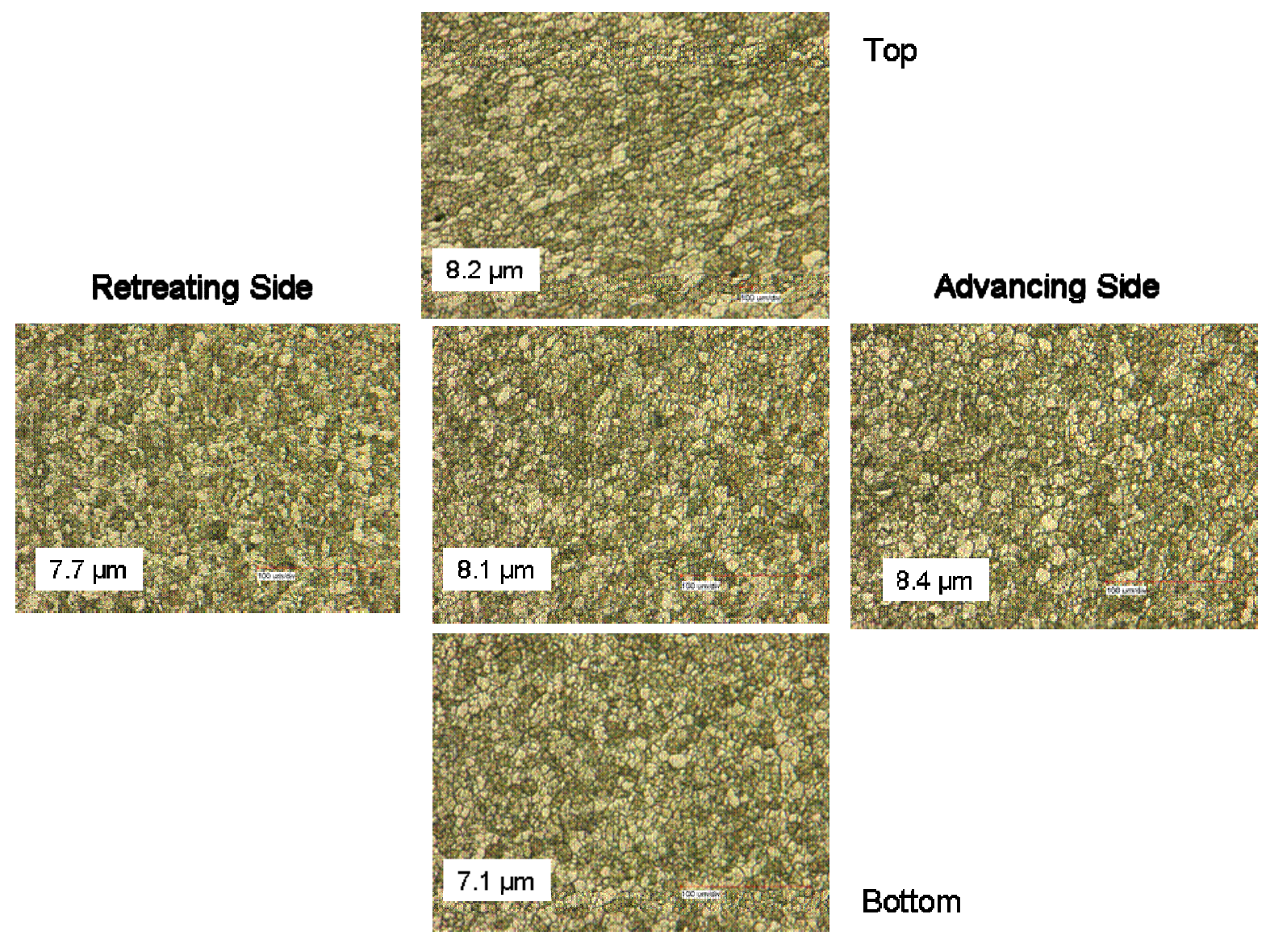

Figure 9 Nugget structure at 1000x at different regions of weld nugget

\subsection{Surface Roughness}

The surface roughness resulting from laser peening, and shot peening is illustrated in Figures 10, and 11 below. Figure 10 illustrates the surface and the profile of the weld nugget for the unpeened, shot and laser peened specimens. The surface profile of the base material and the laser peened specimen did not differ significantly. In contrast, shot peening resulted in significant surface roughness. 


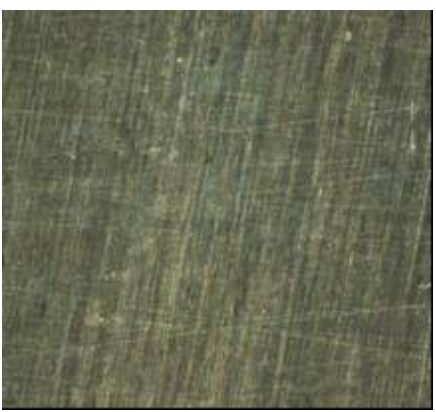

Base Material

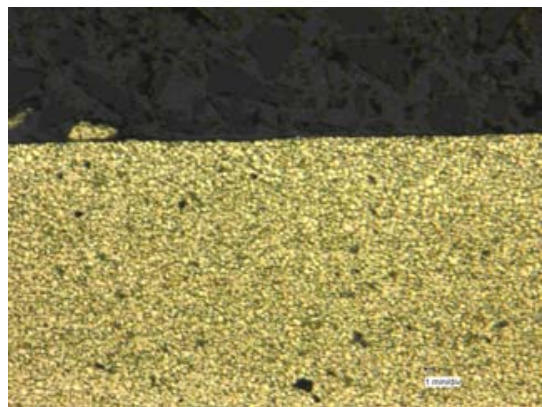

Base Material

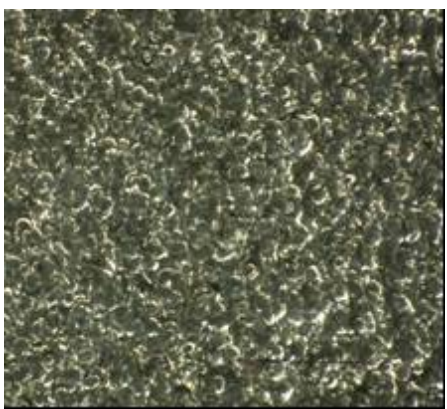

Shot Peening

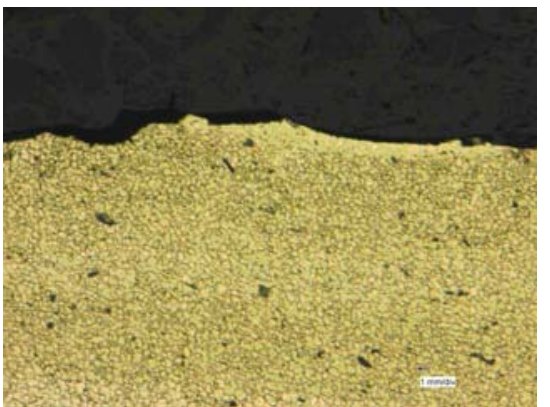

Shot Peening

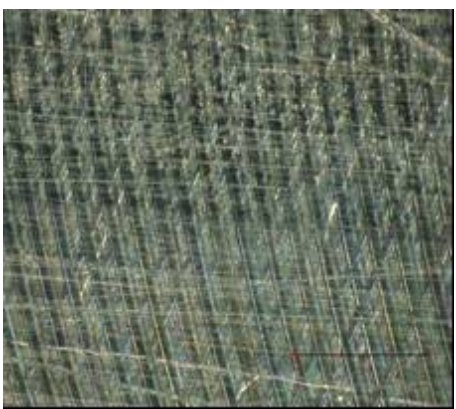

Laser Peening

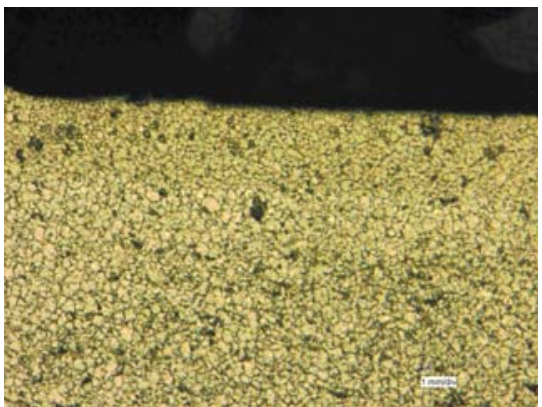

Laser Peening

Figure 10: Different surface roughness resulting from different peening

\section{techniques}

The 2-D surface traces on the specimen were $50 \mathrm{~mm}$ long in a direction

perpendicular to the weld region. A comparison of the roughening effects of the

unpeened, laser peening, and shot peened specimens are shown in Table 2.

Table 2. Average and Peak surface roughness values

\begin{tabular}{|c|c|c|}
\hline Condition & Ra $(\boldsymbol{\mu m})$ & Rt $(\boldsymbol{\mu m})$ \\
\hline Unpeened FSW & 0.24 & 3.97 \\
\hline Shot Peened & 3.8605 & 44.831 \\
\hline Laser Peened & 0.347 & 5.5375 \\
\hline
\end{tabular}


Figure 11 illustrates the 3D surface roughness taken on an $8 \times 8 \mathrm{~mm}$ area in the weld nugget region. Highest roughness was exhibited by the shot peening process, leading to large increases in the value of the mean and peak roughness. Specimen processed with laser peening had a relatively smooth surface compared to the base material. Surface morphology can have a big impact of the fatigue life behavior. It is possible the some of the gains from shot peening can be reduced by the adverse surface roughness on the specimen surface. A recent study by Honda [29] showed that an increase in the arithmetic mean roughness $\mathrm{Ra}$ and the peak to valley height $\mathrm{Rt}$ led to increased stress concentration which offset the attendant increase in compressive residual stresses. The roughening effects of the unpeened, laser peened, and shot peened specimens for the nugget region are shown in Table 3.

Table 3. Average and Peak surface roughness values for the nugget region

\begin{tabular}{|r||r||r|}
\hline Condition & Ra $(\boldsymbol{\mu m})$ & Rt $(\boldsymbol{\mu m})$ \\
\hline Unpeened FSW & 0.38 & 5.94 \\
\hline Shot Peened & 7.59 & 73.7 \\
\hline Laser Peened & 2.88 & 20.6 \\
\hline
\end{tabular}




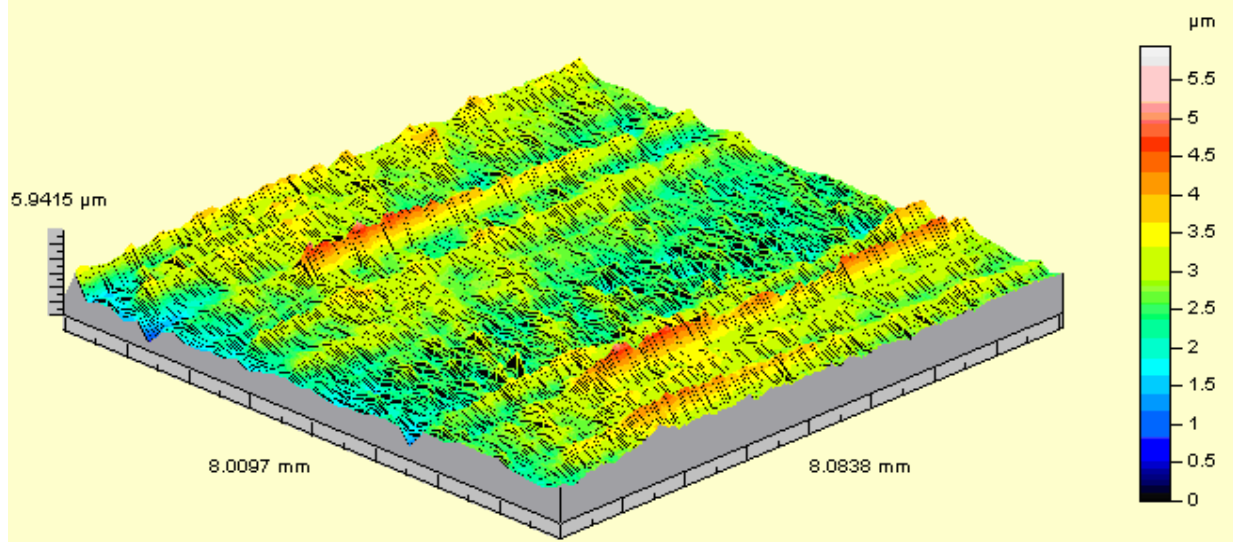

\section{Unpeened FSW}

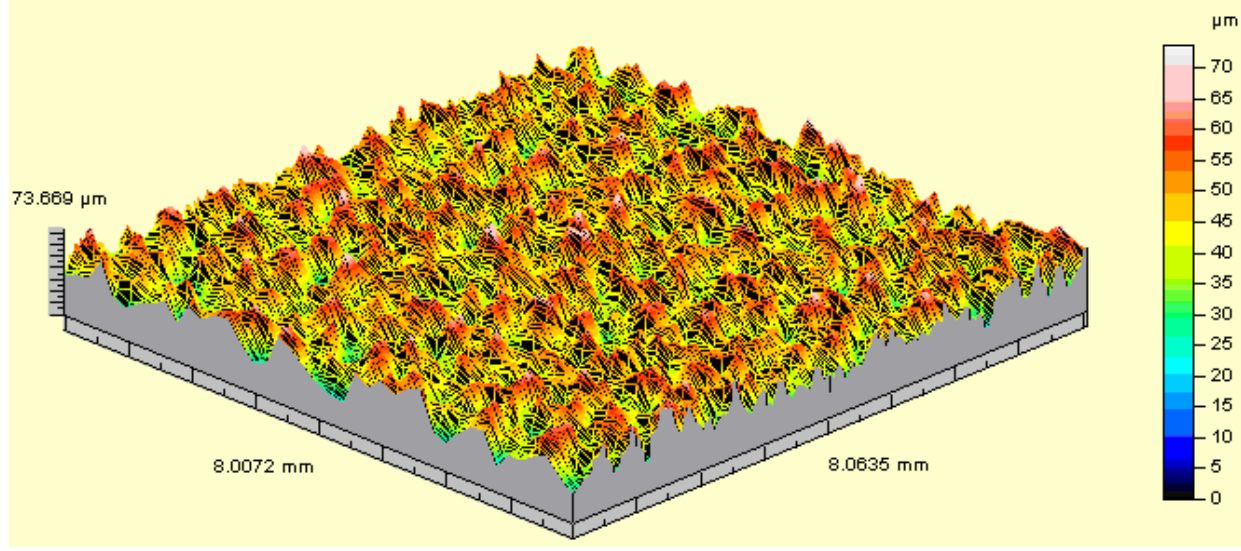

Laser Peened (Double Layers)

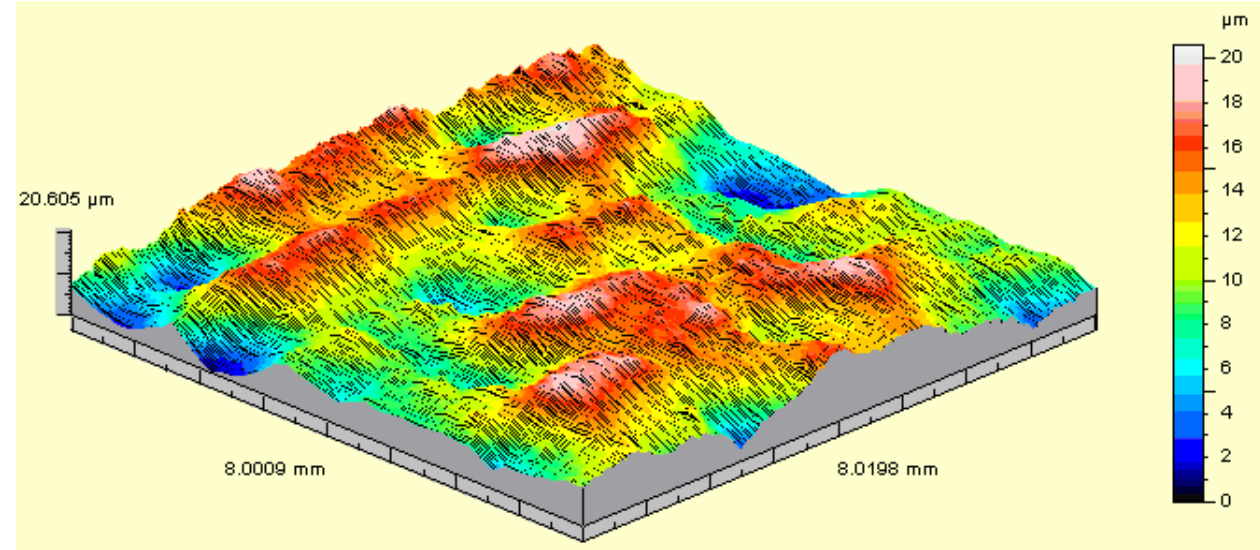

Laser Peened (Triple Layers)

Figure 11: A 3d contour of the surface roughness resulting from the unpeened specimen 
Figure 12 illustrates the surface roughness at the weld nugget and the base material for a specimen processed with laser peening. The softer material at the weld resulted in higher roughness when compared to the base material.

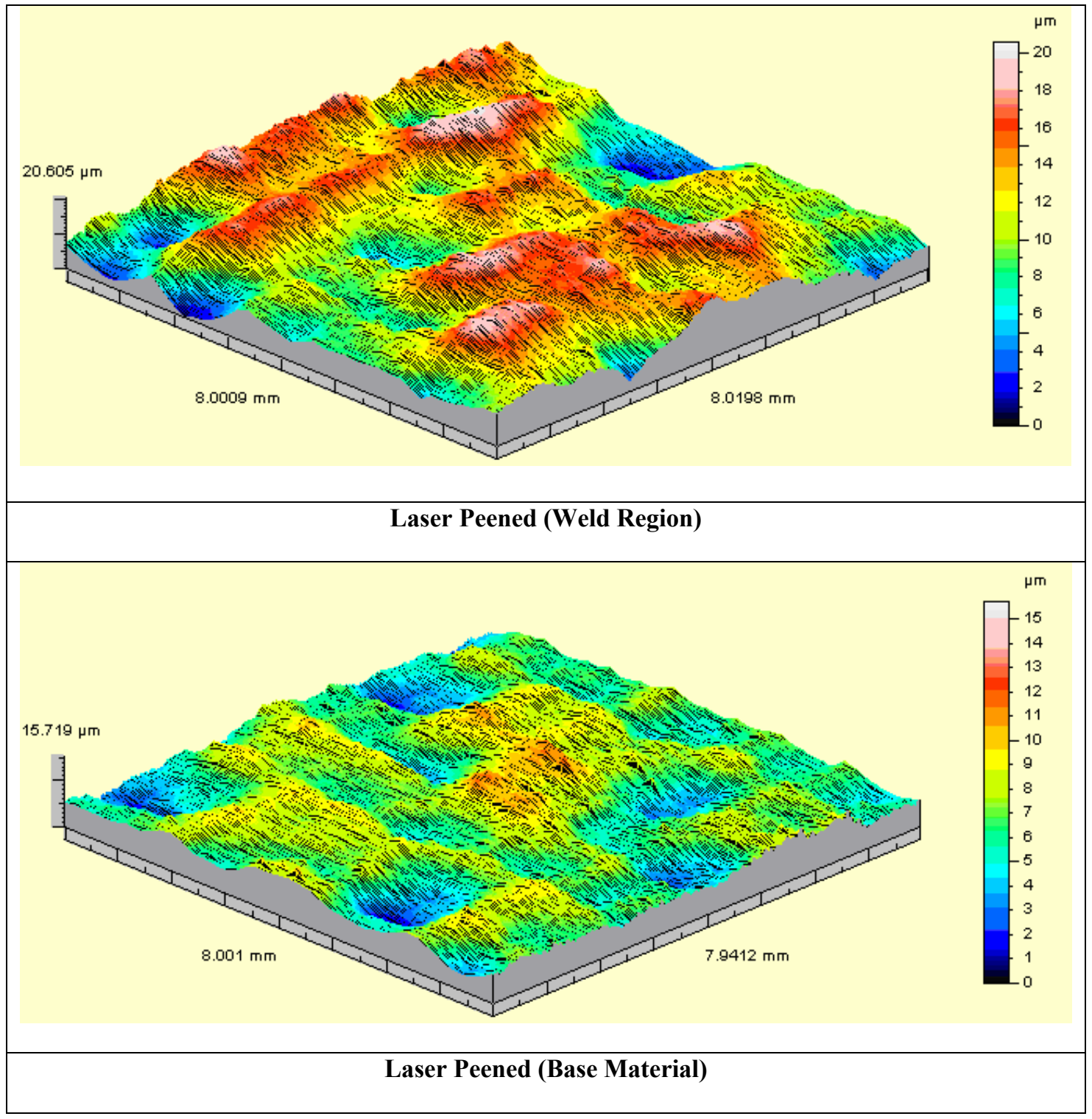

Figure 12: A 3d contour of the surface roughness resulting from the unpeened specimen 


\subsection{Surface Residual Stress}

The residual stresses at different locations across the weld are shown in Figures 13 and 14 below. The stresses were measured in both longitudinal and transverse directions using the x-ray diffraction technique.

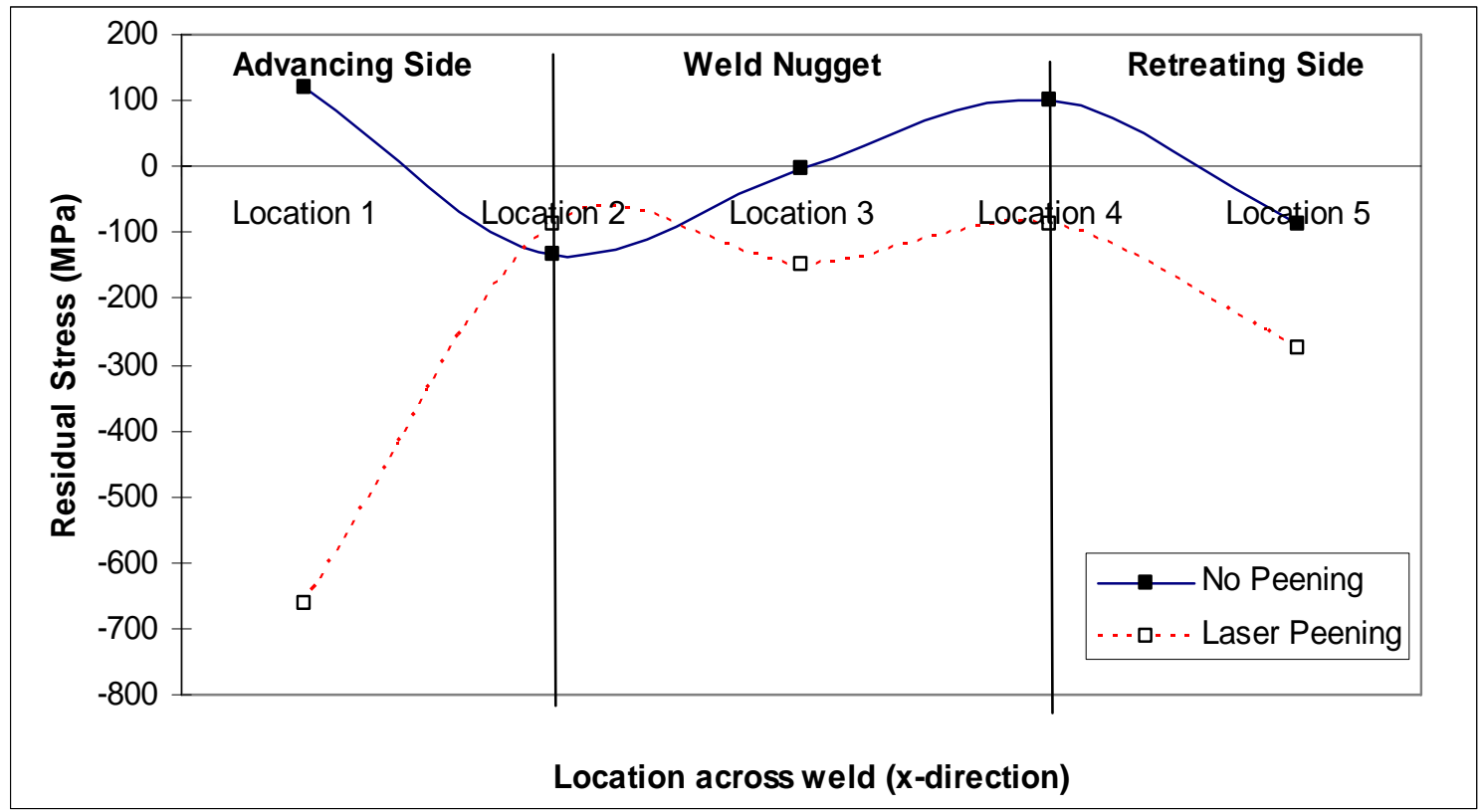

Figure 13: Residual stress distribution across the weld (x-direction) 


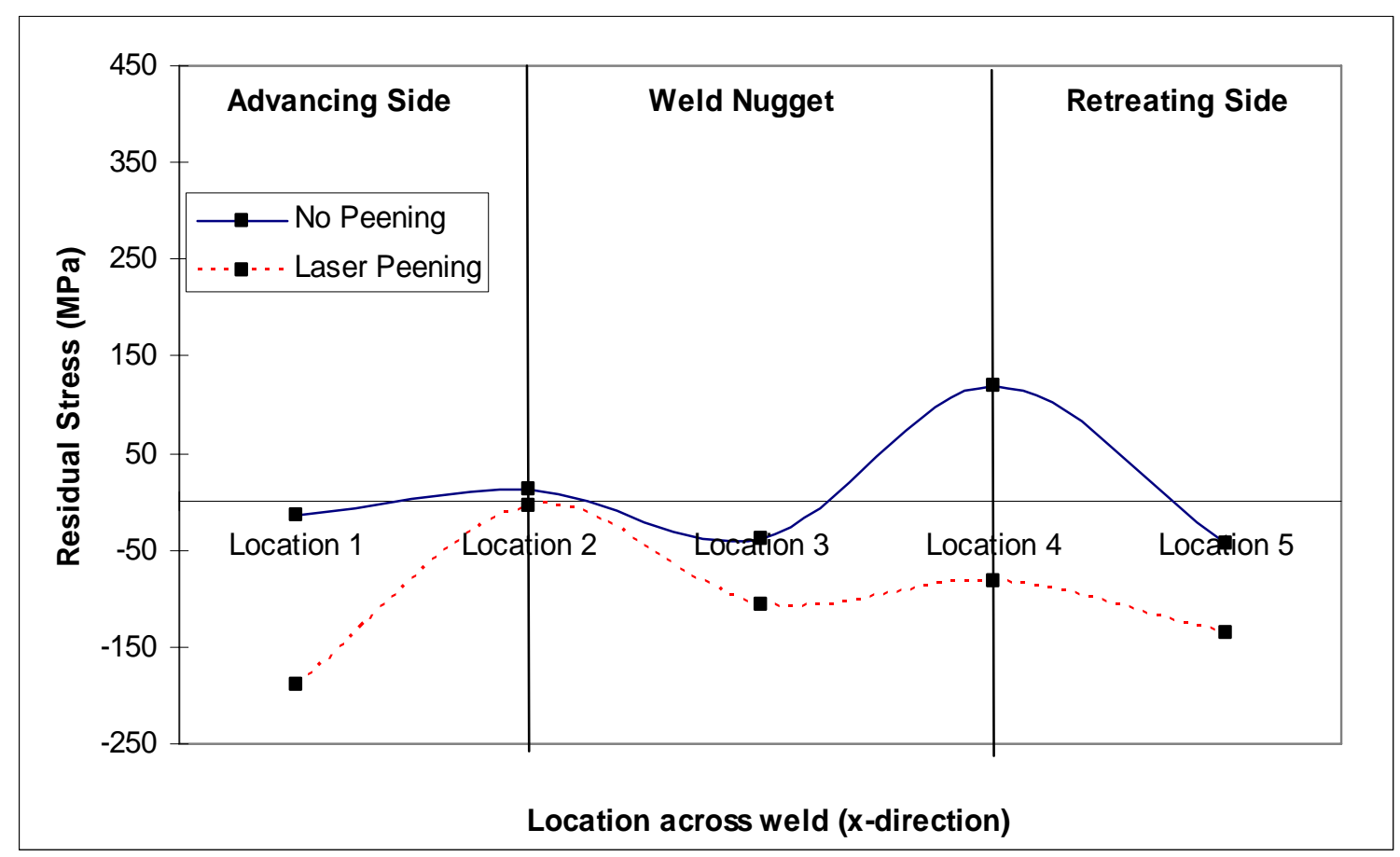

Figure 14: Residual stress distribution across the weld (x-direction)

The residual stresses from the contour method are shown in Figure 15. The magnitude of the measured subsurface residual stresses in the weld in the longitudinal direction was relatively small. This is mainly due to size of the machined specimens cut from the plate after welding which will reduce the amount of residual stress they contain. The effect of laser peening on the through thickness residual stresses of the specimens was relatively small. This is likely due to the fact that the specimens are relatively thin and laser peening was applied over a large area, which means that there is less constraint on the laser peened region to support the compressive residual stress. To equilibrate the compressive residual stress, sub-surface tensile residual stresses develop in the laser peened specimen. 
It is noted that the residual stress component measured will not have a large effect on fatigue performance if the specimen is loaded axially along the $\mathrm{x}$-axis. Thus, these results may not correlate directly with fatigue testing data. In addition, due to the geometry of the specimen, it is likely that the through thickness compressive residual stress produced by laser peening will be greater along the weld transverse direction rather than the longitudinal direction. Also, residual stresses produced by the contour method lack accuracy when trying to predict the stresses at the surface. Therefore, surface stresses were better characterized by the x-ray diffraction method as shown earlier in the section.
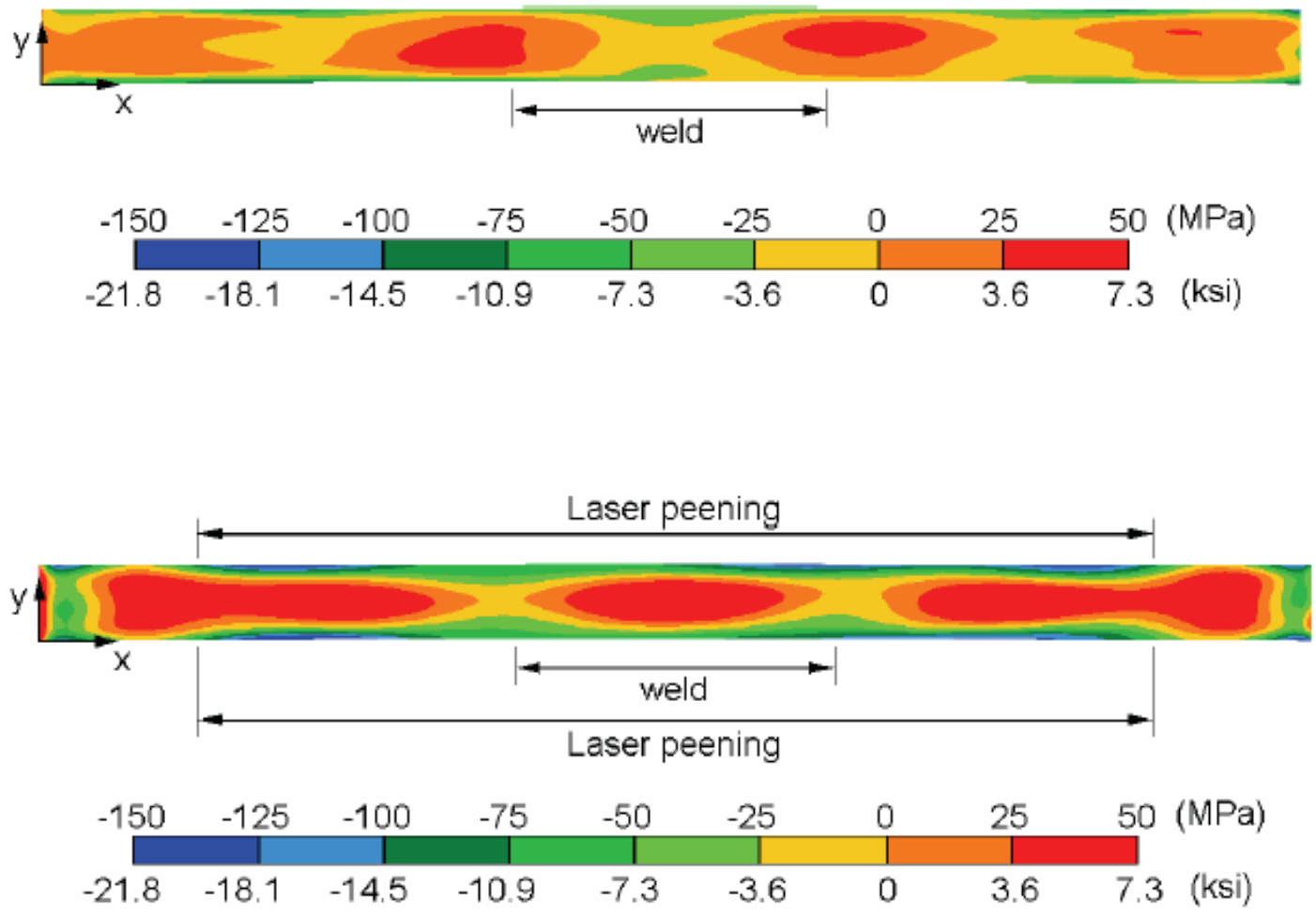


\subsection{Microhardness profiles}

Microhardness measurements were taken across the weld zone as shown in Figure 15. The soft region is probably caused by coarsening and dissolution of strengthening precipitates during the thermal cycle of the FSW. Softening was noted throughout the weld zone. It was also noticed that the lowest hardness levels were at a distance corresponding to the weld interface. The variations in hardness can be correlated to the microstructure developed after the welding process. The hardness levels increased with increasing distance from the weld as precipitation hardening became more effective.

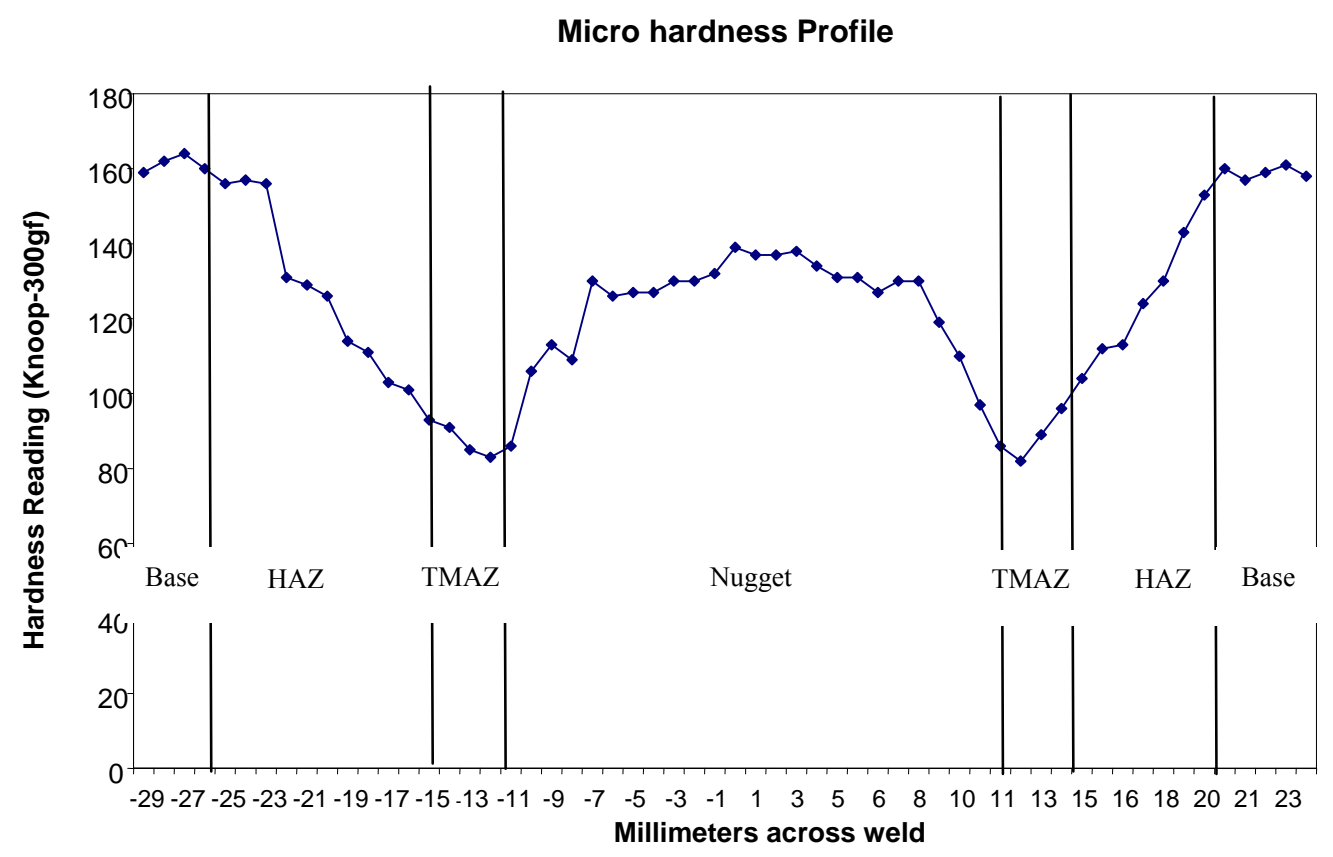

Figure 15 Micro-hardness test across the weld of FSW 7075-T7351 


\subsection{Tensile Testing}

Tensile Test results are shown in Figure 16. The fracture locations were at or near the interface between the weld nugget and the TMAZ on the retreating side of the weld at a 45 degree angle. As shown in Figure 15, the interface between the weld nugget and TMAZ correspond to low hardness area because the original structure in this region is over aged and there is not enough solute left in the material. Therefore, this area of the weld will be relatively ineffective in inhibiting dislocation motion and the strain localization in the softened area of the weld will result in a degradation of the mechanical properties. The consistent failure at that location also suggests that the tensile properties of the welded joint are not symmetric on the two interfaces of the weld, and that the tensile properties on the retreating side are weaker than the advancing side.

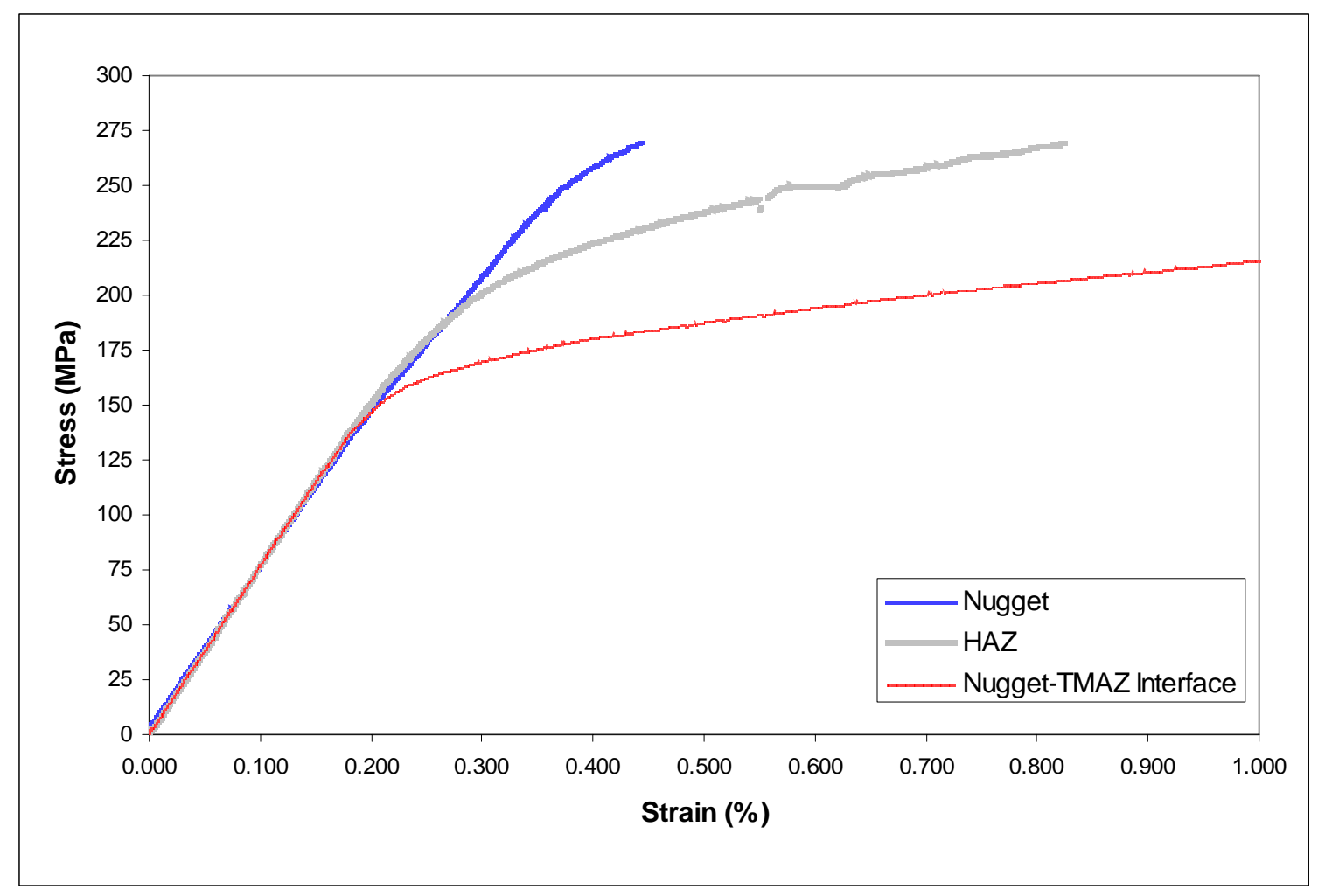

Figure 16 Engineering stress-strain curves for the unpeened FSW AA 7075-T7351 
The tensile properties at the nugget exhibited higher values than at the HAZ location were the strain gage was installed. The lowest tensile properties corresponded to the nugget-TMAZ interface were failure of the joint occurred. The global tensile data for the unpeened FSW 7075-T7351 are shown in Table 3. All properties for the welded specimens were lower than for the base unwelded material.

Table 3. Global tensile properties for the heat treated T7351 and FSW AA 7075-T7351

\begin{tabular}{|c|c|c|c|}
\hline Material & Yield Stress (MPa) & Ultimate Strength (MPa) & Total Elongation (\%) \\
\hline FSW 7075-T7351 & 226 & 339 & 5.5 \\
\hline
\end{tabular}

\subsection{Fatigue life}

Fatigue life changes as a result of shot peening, laser peening, and a combination are shown in Figure 17. The results were also compared to the unpeened FSW in Figure 18. The specimens processed with shot peening indicated around $7 \%$ increase on average in fatigue life when compared to the unpeened FSW samples. On the other hand, specimens processed with laser peening had an increase about $146 \%$ over the unpeened FSW specimens. Previous research $[30,31]$ has shown that the residual stress resulting from laser peening can be significantly higher and deeper than for conventional shot peening. Therefore, the deeper the compressive residual stress, the longer the compressive stress will interact with the crack, resulting in a slower crack growth rate and longer fatigue life. 
Surface roughness from shot peening can also be a major detrimental effect to fatigue life. The high surface roughness from shot peening can lead to local intensification of the far-field stress [32]. This can result in premature initiation and propagation of cracks. The difference in fatigue life results between the shot peening and laser peening could also be attributed in part to the amount of residual stress relaxation that takes place during fatigue cycling. Recent studies [33-35] have shown that the initial residual stress at the surface under service loading can be substantially reduced by relaxation and redistribution during the fatigue cycling. The relaxation due to cyclic loading is mainly affected by the magnitude of the residual stress. Residual stress relaxation starts when the sum of loading and residual stress exceeds the yield strength during cycling [34]. The degree of cold working has been shown to have an important affect on the residual stress relaxation, Zhuang [35] indicated that shot peened specimens generated a high cold work state between $30-40 \%$ while laser peening had a much lower cold working around 4-9\% IN718. Because of the Bauschinger effect, the greater the tensile cold working, the lower the compressive yield strength. Therefore, there will be a higher tendency to cyclically relax the initial compressive residual stress in the shot peened specimens because the compressive yield strength is lowered.

In addition, Peyre [31] showed that very small surface gradients are found after laser peening, while Webster [36] indicated that significant near surface stress gradients are produced by the shot peening process. Since surface gradient plays an important role in the residual stress relaxation, this factor can also have a role in the improved fatigue life in the laser peened specimens. 
The combination of shot and laser peening had an increase of $129 \%$ over the unpeened specimens. Peyre [31] showed that a combination of laser and shot peening treatment in 7075 AA was capable of achieving an optimum residual stress profile at the surface, but did not supplement his data with fatigue testing to show the possibility of fatigue behavior improvement. Therefore the improvement in fatigue life may have been caused by the beneficial residual stress profile from the combined process.

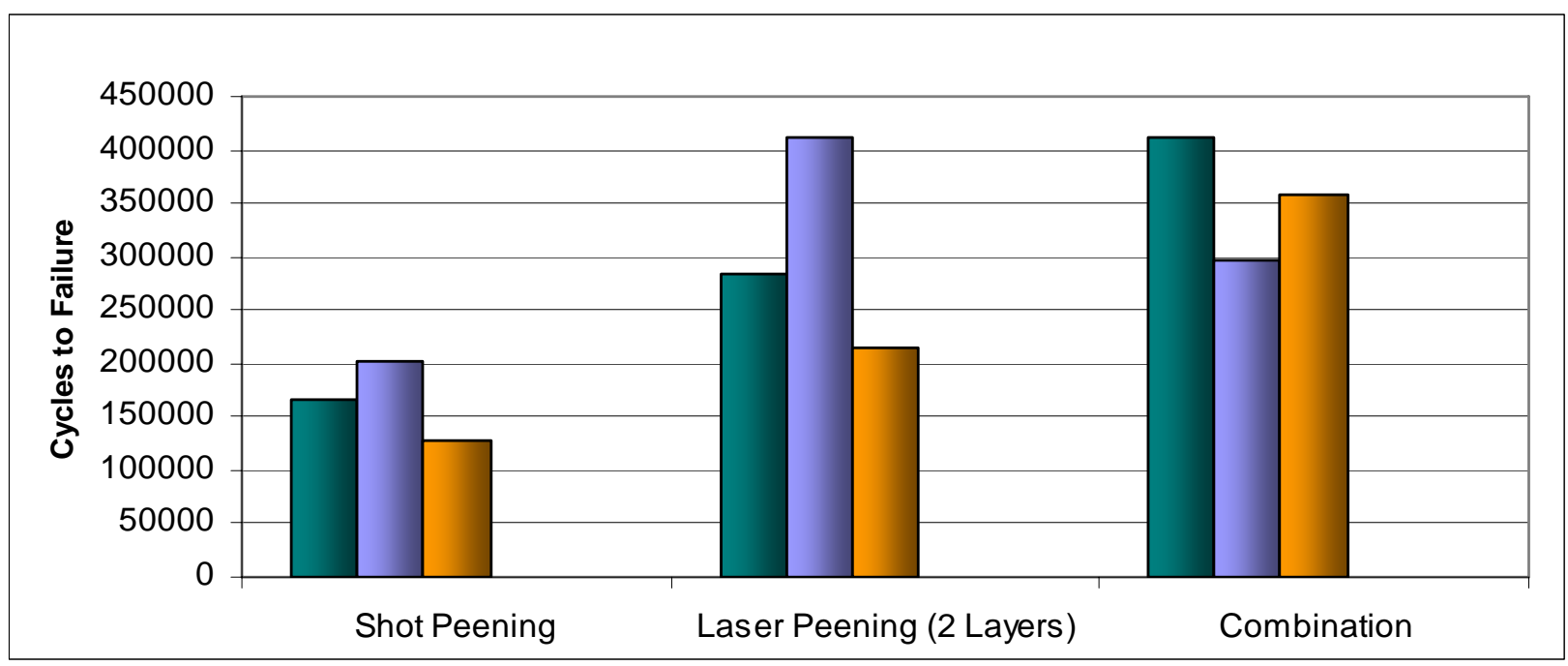

Figure 17: Fatigue life results for the different configurations investigated 


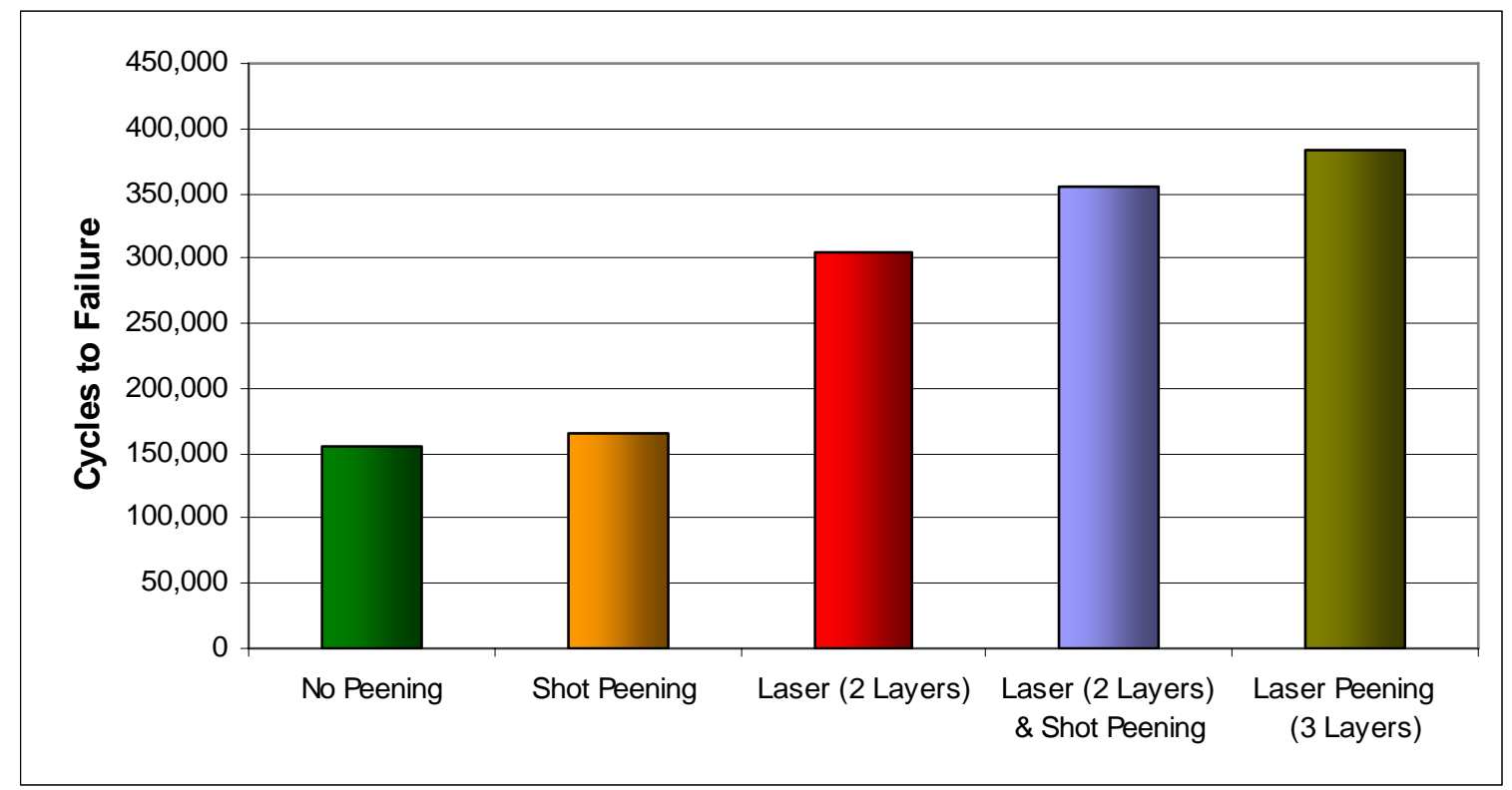

Figure 18: Average fatigue life results for the different configurations investigated

It was noted from the fatigue tests that all laser peened specimens had cracks initiating at the edges, even though the corners of the specimen were rounded. Therefore, it was decided to investigate the effect of the edge roughness on fatigue life of laser peened specimen. A new set of laser peened samples was used in which the specimen's edges were hand polished after peening to achieve a surface roughness similar to the unpeened samples. Fatigue test using the new polished laser peened samples resulted in a significant increase in fatigue life over the unpolished ones as shown in Figure 19. The test data was also compared to base unwelded material. One of the laser peened specimen failed at 219,030 cycles but the failure location corresponded to a location outside the welded region in an unpeened location. The fatigue life tests were stopped at ten million cycles. Even though the laser peened specimens with unpolished edges had a large increase in fatigue life when compared to the unpeened specimen, it is evident from the results in Figure 19 that further enhancing the surface roughness can lead to considerable increases to the fatigue life. 


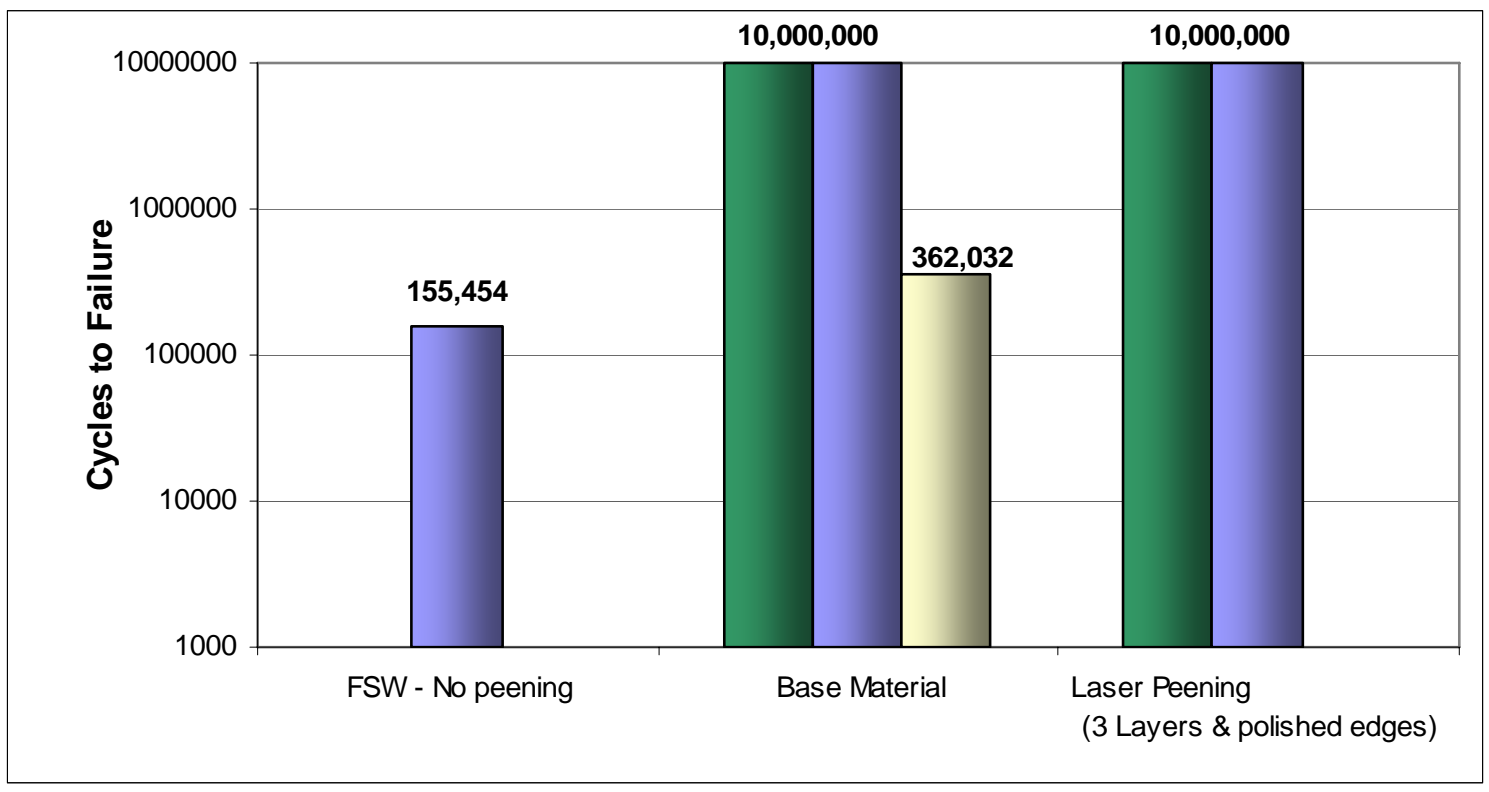

Figure 19: Average fatigue life results for the different configurations investigated

The failure locations on the tested specimens corresponded to a location at or near the weld interface as shown in Figure 20. That location corresponds to a minimum hardness level as evident on the micro harness test in Figure 15. This data seem to confirm the results obtained by Bussu [37] on FSW 2024-T351. Peyre [31] indicated that cumulative laser peening impacts on 7075 resulted in increased residual stress levels in the superficial layers. In addition, the numerous laser peening impacts caused local cyclic hardening.

A study by Song [38] helped explain whether the improvement in fatigue was due to the increase in harness level or due to the crack closure caused by the compressive residual stresses from the laser peening. The results from [38 study revealed that strain hardening introduced by shot peening was not the main reason for suppressing crack propagation in peened fatigued specimen. It was postulated that crack closure was the cause for the crack growth retardation. He came to that conclusion in view of the fact 
that specimens peened behind the crack tip where the influence of strain hardening on the crack tip was inconsequential, had better crack retardation than specimens peened in front of the crack tip.

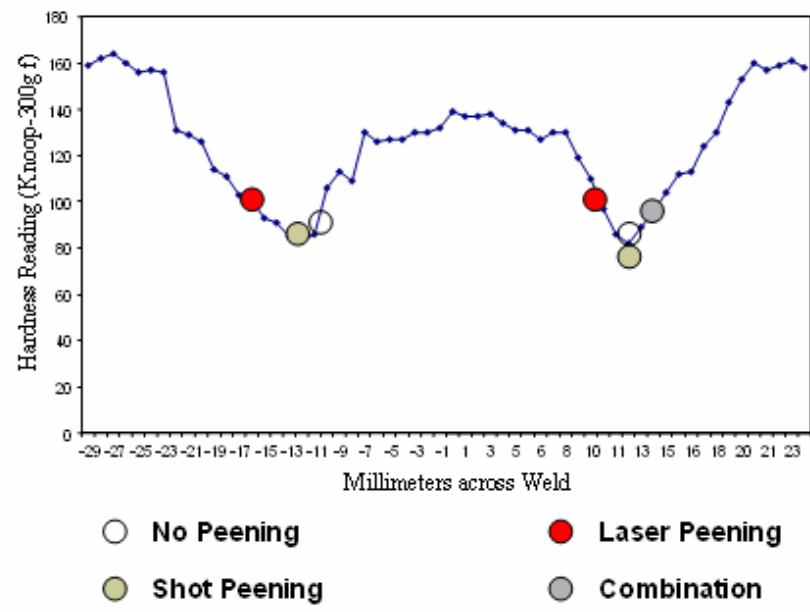

Figure 20: Fatigue life results for the different configurations investigated

\subsection{Fractography}

Fatigue crack initiation sites of the fractured specimens were either in the root or in the crown region of the parts. Figure 21 illustrates the fracture surface for a shot peened specimen tested at $190 \mathrm{MPa}(\mathrm{N}=226,000$ cycles $)$. The Figure also illustrates the crack initiation, propagation and overload region. All specimens processed with this technique exhibited multiple cracks on the fracture surface. That is mainly due to the high surface roughness introduced by the shot peening technique. The dimple fracture surfaces revealed features reminiscent of locally ductile failure. Stable crack growth occurred by mechanisms that resulted in the formation and presence of striation like features.

Fatigue striation patterns were clearly visible on the fractured surfaces of the tested FSW 7075-T7351 specimens. Nevertheless, the fatigue striations spacing for the 
laser peened specimens were reduced when compared to the un-peened, and shot peened specimens. This reduction in striation spacing indicates a slower FCG rate and is partially attributed to the compressive residual stresses induced by the laser peening.

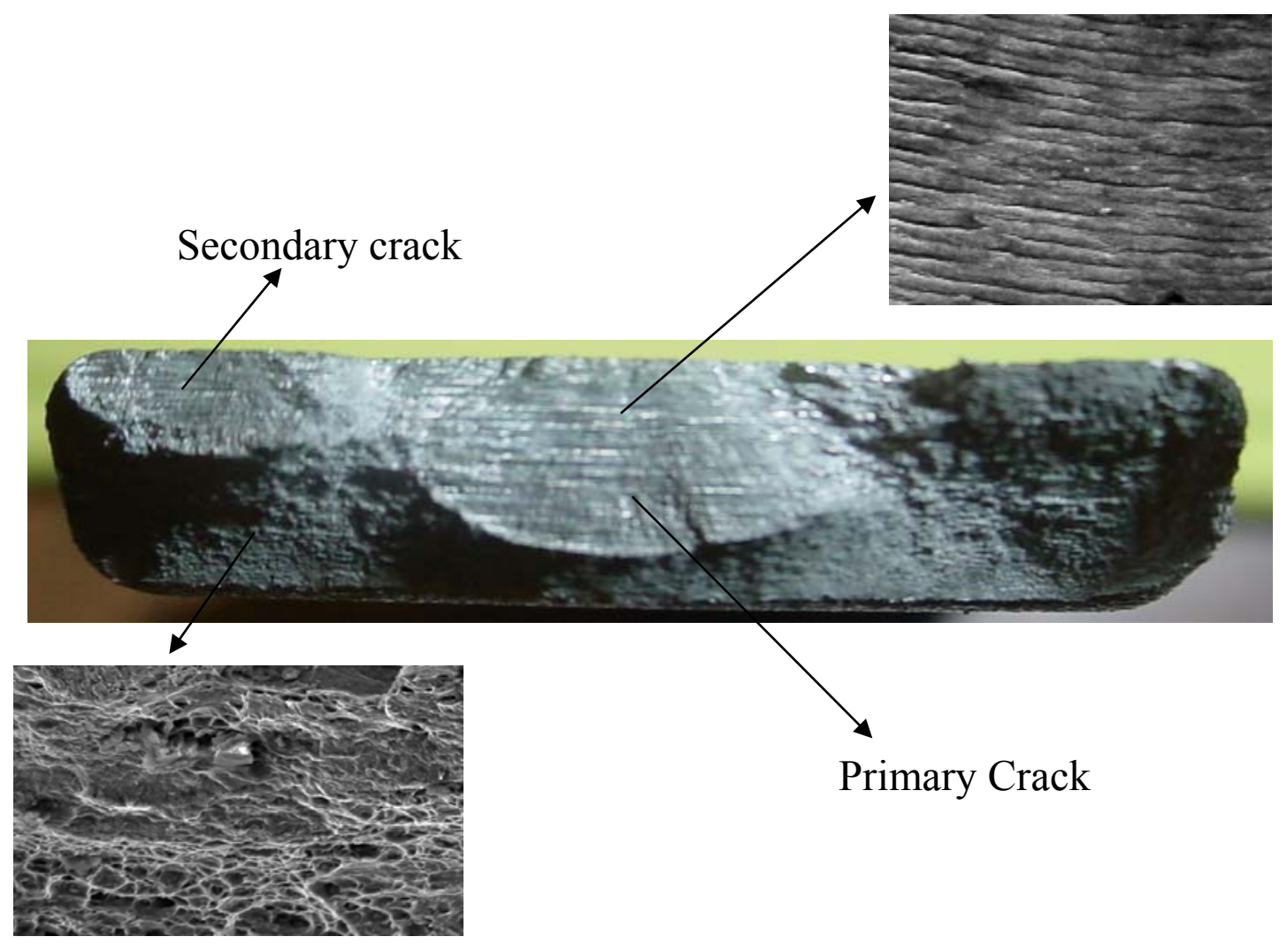

Figure 21: Fractographic analysis for different regions of the shot peened specimen fracture surface

\section{$4 \quad$ Summary and Conclusion}

The fatigue life effects of laser peening, shot peening and a combination of both was investigated on Friction Stir Welds AA 7075-T7351. The loading was applied in a direction perpendicular to the weld direction. Laser peening parameters were developed by testing a small population of specimen for best fatigue performance. The fatigue life of the specimens was dominated by the corner singularity, to better quantify the effects of 
the different peening techniques, the corners were rounded. The residual stresses at the surface and subsurface were characterized using the x-ray diffraction and the contour method. Surface roughness was also assessed for the different peened conditions. Shot peening resulted in significantly higher surface roughness compared to the base material. On the other hand, specimens processed with laser peening were relatively smooth. The laser peening can effectively lengthen the fatigue life in the tested FSW specimen, but it is recommended to supplement this study with a higher number of specimens to obtain a more statistically acceptable data.

\section{Acknowledgment}

The authors are grateful to Mrs. Irene E. Kaye, Mr. Joseph E. Rogers, and Mr. Gregory F. Galbreath from the NASA Johnson Space Center for their logistical support for this project. The authors are also grateful to Mr. Chip Moore from NASA Marshal Space Center for his assistance with the surface measurements, and Dr. Lloyd Hackel from the Metal Improvement Company for his valuable comments. 


\section{References}

1 Thomas W. M et al. Friction stir butt welding. Int Patent App PCT/GB92/02203, and GB Patent App 9125978.8, December 1991. US patent No. 5, 460,317, October 1995

2 Kroninger, H.R, Reynolds, A. P. R-curve behavior of friction stir welds in aluminum-lithium alloy 2195. Fatigue Fract Engineering Mater Struct, (2002) 25, $283-290$

3 Sutton, M. A, Reynolds, A. P. et al. A study of residual stresses and microstructure in 2024-T3 aluminum friction stir butt welds. Journal of Engineering Materials and Technology (2002) Vol. 124. 215-221

4 Mishra R. S. et al. Friction Stir Welding and Processing. Materials Science and engineering R 50 (2005) 1-78.

5 Donne, C. D. et al. Investigations on Residual Stresses in Friction Stir Welds. 3'rd International Symposium on Friction Stir Welding, Kobe, Japan 2001.

6 Bussu G. et al. The Role of Residual Stress and Heat affected Zone Properties on Fatigue crack propagation in friction stir welded 2024-T351 aluminum joints. International Journal of Fatigue 25 (2003) 77-88

7 Biallas G, Dalle Donne C, Juricic C. Monotonic and cyclic strength of friction stir welded aluminium joints. In: Miannay D, Costa P, Franc, ois D, editors. Advances in mechanical behaviour plasticity and damage. Proceedings of EUROMAT 2000, vol. 1. Amsterdam: Elsevier; 2000. p. 115-20 
8 Magnusson L, Kallman L. Mechanical properties of friction stir welds in thin sheet of aluminium 2024, 6013 and 7475. Second international symposium on FSW, Gothenburg, Sweden, June 2000

9 Maddox SJ. Review of fatigue assessment procedures for welded aluminum structures. Int J Fatigue 2003;25:1359-78

10 James MN, Bradley GR. Weld tool travel speed effects on fatigue life of friction stir welds in 5083 Aluminium. Int J Fatigue 2003;25: 1389-98

11 Ericsson M, Sandstrom. Influence of welding speed on the fatigue of friction stir welds and comparison with MIG and TIG. Int J Fatigue 2003;25:1379-87

12 Dickerson TL. Fatigue of friction stir welds in Aluminum alloys that contain root flaws. Int J Fatigue 2003;25:1399-409

13 Okura I, Naruo M, Vigh LG, Hagisawa N, Toda H. Fatigue of aluminum deck fabricated by friction stir welding. Eighth international conference INALCO 2001

14 Banes, M. et al. Fatigue properties of as-welded AA6005 and AA6082 aluminum alloys in T1 and T5 temper condition. Trends in Welding Research, Proceedings of the $4^{\text {th }}$ International Conference, 5-8 June 1995, Gatlinburg, Tennessee.

15 Donne, C, et al. Fatigue and Fracture performance of friction stir welded 2024-T3 joints. Proceedings European Conference on Spacecraft Structures, Materials and Mechanical Testing, Brauschweig, Germany, 4-6 November 1998.

16 Russel, S. et al. Static, fatigue and crack growth behavior of friction stir welded 7075-T6 and 2024-T3 aluminum alloys. Friction Stir Welding and Processing. The Minerals, Metals \& Materials Society) 2001. pp 93-104. 
17 Donne, C, et al. Effect of weld imperfections and residual stresses on the fatigue crack propagation in friction stir welded joints. Second International Conference on Friction Stir Welding, 26-28 June 2000. Gothenburg, Sweeden.

18 J. M. Yang at al. Laser shock peening on fatigue behavior of 2024-T3 Al alloy with fastener holes and stopholes. Materials Science and Engineering A298 (2001) 296-299

19 C. Rubio-Gonzalez et al. Effect of laser shock processing on fatigue crack growth and fracture toughness of 6061-T6 aluminum alloy. Materials Science and Engineering A 386 (2004) 291-295

20 J. S Romero et al. Effects of Controlled Shot Peening and Laser Shot Peening on Fatigue Performance of 2024-T351 Aluminum Alloy. Journal of Materials Engineering and Performance. Vol. 12. Issue 4. Aug 2003. 414-419

21 P. Peyre at al. FEM simulation of residual stresses induced by laser Peening. Eur. Phys. J. AP 23, 83-88 (2003)

22 John, R., et al. Residual stress effects on near-threshold fatigue crack growth in friction stir welds in aerospace alloys. International Journal of Fatigue 25 (2003) 939-948

23 Mahoney, M. W. et al. Properties of friction -stir-welded 7075 T651 aluminum. Metallurgical and Materials Transactions A. Volume 29A, 1998. pp 1955-1964.

24 Lockwood, W. et al. Mechanical response of friction stir welded AA2024: Experiment and modeling. Material Science and Engineering A323 (2002) 348353. 
25 Tan Y. et al. Laser shock peening on fatigue crack growth behavior of aluminum alloy. Fatigue and Fracture of Engineering Materials. 27, 649-656.

26 J. K. Gregory, H. J. Rack, and D. Eylon (eds.) Surface Performance of Titanium, TMS, Warrendale, PA. (1996) pp. 217-230

27 M.B. Prime, "Cross-sectional mapping of residual stresses by measuring the surfacecontour after a cut," Journal of Engineering Materials and Technology, $123,162-168$ (2001).

28 Jata K et al. Metall Materials Transactions. 2000, 31A. 2181-2192.

29 Honda T. et al. Effect of shot peening on fatigue crack growth in 7075-T7351. Journal of ASTM International, 2005, Vol. 2, No. 6.

30 C. Montross et al. Laser shock processing and its effects on microstructure and properties of metal alloys: a review. International Journal of Fatigue 24 (2002) 1021-1036

31 P. Peyre at al. Laser shock processing of aluminium alloys. Application to high cycle fatigue behaviour. Material Science and Engineering A210. (1996) 102-113

32 Rodopoulos C. et al. Effect of controlled shot peening and laser shock peening on the fatigue performance of 2024-T351 aluminum alloy. Journal of Materials Engineering and performance. Volume 12 (4) 2003 414-419.

33 Boyce B. et al. The residual stress state due to spherical hard-body impact. Mechanics of Materials 33 (2001) 441-454.

34 Holzapfel H. el at. Residual stress relaxation in AISI 4140 steel due to quasistatic and cyclic loading at higher temperatures. Material Science and Engineering A 248 (1998) 9-18

35 Zhuang W. et al. Investigation of residual stress relaxation under cyclic load. International Journal of Fatigue 23 (2001) S31-S37 
36 Webster G. et al. Residual stress distribution and their influence on fatigue lifetimes. International Journal of Fatigue 23 (2001) S375-S383.

37 Bussu G. et al. Fatigue performance of friction stir welded 2024-T351 aluminium joints. 1'st international symposium on FSW. California 1999.

38 Song P. et al. Crack closure and crack growth behaviour in shot peened fatigued specimen. Engineering Fracture Mechanics 63 (1999) 295-304. 